\title{
Language Deficits or Differences: What We Know about African American Vernacular English in the 21st Century
}

\author{
Yvette R. Harris $^{1} \&$ Valarie M. Schroeder ${ }^{1}$ \\ ${ }^{1}$ Department of Psychology, Miami University, Oxford, Ohio, USA \\ Correspondence: Yvette R. Harris, Department of Psychology, 210 Psychology Building, Miami University, \\ Oxford 45056, Ohio, USA. Tel: 1-513-529-2900. E-mail: harrisyr@miamiOH.edu
}

Received: January 24, 2013

Accepted: February 5, 2013 Online Published: March 26, 2013

doi:10.5539/ies.v6n4p194

URL: http://dx.doi.org/10.5539/ies.v6n4p194

\begin{abstract}
This focus of this paper is to present an overview of the current research which examines the language and literacy performance of African American children who speak African American Vernacular English (AAVE), as presented from a deficit versus difference perspective. Language and literacy and assessment and remediation of AAVE speakers are discussed in sections one and two. Section three of the paper provides theoretical and methodological suggestions to educational psychologists, speech pathologists and developmental psychologists investigating AAVE speakers, on ways to gain a better appreciation for, and understanding of, the intricacies associated with African American Vernacular English. The paper closes with a discussion of the litigation and controversies surrounding AAVE.
\end{abstract}

Keywords: AAVE, African vernacular English, Ebonics, language deficits

\section{Introduction}

For more than four decades tensions have existed among scholars, educators, and psychologists with reference to the legitimacy of African American Vernacular English (AAVE) as a language system. Those embracing a deficit view have expressed their concern about the language and literacy performance of African American children who speak AAVE (Harris \& Graham, 2007). According to these experts, the comparatively low performance of African American children on standardized literacy activities is due in part to their deficient speech and language pattern. That is, features of African Vernacular English interfere with their performance on classroom language and literacy activities. In contrast, researchers, educators (i.e., 1996, Ebonics Resolution), and parents (i.e., "The Ann Arbor Black English Case") supporting a difference view argue that AAVE is a legitimate language with its own rules for pronunciation, grammar, syntax, and semantics. These scholars have encouraged the discipline to make a "paradigm shift" with a movement from viewing children who use AAVE as being deficient in speech and language performance towards viewing these children as simply using a different speech pattern (Stockman, 2010).

This paper is divided into four sections. Section one discusses the language and literacy outcomes of AAVE speakers. The second section of the paper considers the issue of assessment and remediation, with a focus on identifying how to assess literacy in AAVE speakers and what steps should be taken towards remediation. Section three offers suggestions for developmental psychologists and others who conduct research on African American children who speak AAVE on employing appropriate theoretical frameworks and methodological approaches. The paper closes with a discussion of the controversy and litigation surrounding AAVE, with a specific focus on the 1974 Ann Arbor School Board ruling and the 1996 decision by the Oakland school board to use AAVE as a pedagogical tool to remedy the poor literacy performance of African American children.

\section{Language and Literacy Outcomes of AAVE Speakers}

Despite the significant differences in language and literacy performance between African American and White students, and despite the trend that has historically viewed AAVE as a deficient language system, African American children have fairly similar developmental trends in language learning as compared to White children (for a comprehensive review see Stockman, 2010). Specifically, prelinguistic characteristics encountered with infants, and then later elements of sentence construction, develop similarly for both African American and White children (Blake, 1994; Harris \& Graham, 2007; Velleman \& Pearson, 2010). In fact, by the time African 
American children enter school, they have developed highly skilled socio- linguistic abilities rich in detail (Beaulieu, 2007; Harris \& Graham, 2007). Despite such similar developmental trends, differences have been documented regarding language and literacy outcomes between AAVE and SAE speakers.

Research has demonstrated mixed views on language and literacy outcome differences between African American and European American children. Specifically, some studies have reported that African American children score lower on tests of verbal ability (e.g., the Peabody Picture Vocabulary Test III; Champion, Hyter, McCAbe, \& Bland-Stewart, 2003; Qi, Kaiser, Milan, \& Hancock, 2006; Qi, Kaiser, Milan, Yzquierdo, \& Hancock, 2003; Restrepo et al., 2006) and reading achievement (Charity, Scarborough, \& Griffin, 2004). Conversely, other studies have demonstrated the opposite, in that African American children show no significant difference on tests of expressive vocabulary (Thomas-Tate, Washington, Craig, \& Packard, 2006) or oral and written language proficiency (Rivers, Rosa-Lugo, \& Hedrick, 2004). However, an important aspect of language development and development in general not to be overlooked is socioeconomic status (SES).

Scholars have documented for years, and continue to do so, the association between low SES and poorer academic and social achievement (McLoyd, 1990). Poverty rates are significantly greater for African Americans as compared to Whites (FIFCFS, 2008), and significantly fewer African Americans attain post-secondary educational diplomas as compared to Whites (U.S. Census Bureau, 2010). Together, these elements are likely to contribute towards significantly greater chances of poorer language development for African American children. Moreover, considering that more African American children live in poverty and low-income households as compared to non-African American children, it is likely that there is even less time for observation of conversation or instruction of language skills with the parent due to the need to maintain employment. Consequently, studies that have examined SES in relation to language and literacy outcome differences between African American and European American children can often attribute SES to the differences (Champion et al., 2003; Qi et al., 2006; Qi et al., 2003; Restrepo et al., 2006; Terry, Connor, Thomas-Tate, \& Love, 2010), and studies in which differences did emerge but in which SES was not examined, typically tested children of low SES (Charity et al., 2004), and thus could potentially indicate poor performance due to SES status rather than AAVE use.

Another line of research that has contributed immensely to the field and which could explain potential differences in language and literacy outcomes is the understanding of dialect switching (Connor \& Craig, 2006; Craig \& Washington, 2004; Thompson, Craig, \& Washington, 2004). Specifically, children are able to switch from AAVE to SAE use dependent upon the task. Connor and Craig (2006) and Thompson and colleagues (2004) both examined vocabulary and literacy skills in African American preschoolers identified with using AAVE. Their assessment techniques incorporated multiple contexts (i.e., oral narrative elicitation and sentence imitation, and picture description, writing, and reading, respectively) for which expectations for the use of AAVE or SAE could be implicitly or explicitly surmised. Results suggest that children hold an awareness of when AAVE use is deemed acceptable, and as such are able to switch between standard and non-standard dialects (Connor \& Craig, 2006). Specifically, children were more apt to use SAE for tasks involving writing or sentence imitation, but AAVE for tasking involving more verbal assessments, such as the narrative elicitation and picture description task. Without this assessment of multiple contexts, this important aspect of AAVE use would have gone unnoticed in assessments of AAVE use in single contexts. Additionally, Connor and Craig (2006) demonstrated that current level of vocabulary use was not related with AAVE use, debunking the myth that children who use AAVE demonstrate deficient language skills.

Further evidence of dialect shifting has been identified. Horton-Ikard and Miller (2004), in a study of African American school-aged children from middle income families, found that AAVE use was more frequent in narrative tasks for males, but more frequent in conversation tasks for females. Additionally, older children showed a decreased trend of AAVE use than younger children. Importantly, older African American children show no difference in language and literacy outcomes than their counterparts, suggesting that any potential differences that may have been present in early childhood become negligible in adolescence. This could be due to more exposure to, or familiarity with, SAE Charity et al., 2004). Such findings suggest that AAVE speakers may tend to adopt SAE as a second language for which they must learn to use in specific circumstances and environments (Beaulieu, 2002; Connor \& Craig, 2006). However, despite such indications that language and literacy performance are often more closely tied to SES factors than AAVE use, and that AAVE speakers are capable of switching between dialects, African American children are often wrongly assessed with having speech and language disabilities and are placed into remedial contexts. 


\section{Assessment and Remediation}

African American children are of the highest percentage of children enrolled in special education and remedial classes (Gravois \& Rosenfield, 2006) in the United States. Although socioeconomic status may account for some of this rate of disproportionality as socioeconomic status is highly believed to contribute to academic and social achievement (McLoyd, 1990), and given that the number of African American children living in poverty is significantly greater than for White children (FIFCFS, 2008), enrollment rates for remedial help in the classroom are still disproportional considering that only approximately $17 \%$ of children enrolled in U.S. schools are of African American ethnicity (U.S. Department of Education, 2010).

Historically, children speaking AAVE were believed to have deficient language skills, as they consistently underperformed on standardized tasks and assessments compared to a normative population of White, middle-class children (Graham, 1992). Some investigators believed that these deficient language skills were a result of AAVE linguistic rules interfering with the learning of SAE (Scott \& Marcus, 2001). Such beliefs, we now realize, have little empirical support, as these assessments failed to incorporate diverse samples into the standardization procedures, and would therefore prove irrelevant to assessing culturally and ethnically diverse populations (Campbell, Dollaghan, Needleman, \& Janosky, 1997). Moreover, cross-cultural comparisons that failed to account for varying socioeconomic status across groups inadequately captured cultural differences. As such, the theory that posited children who use AAVE experience deficient language skills was challenged due to inappropriate assessment measures and research methodology. Importantly, studies sensitive to historically erroneous assessments and methodologies showed no measurable differences of literacy skills between AAVE and SAE speakers (Harris \& Graham, 2007; Terry, Connor, Thomas-Tate, \& Love, 2010).

The move away from the deficit theory brought about a renewed awareness of assessment techniques and methodology by researchers by which to capture language and literacy skills of children who use AAVE. Researchers were beginning to notice that AAVE use was influenced by the context of the task generating language use (Connor \& Craig, 2006; Craig \& Washington, 2004; Thompson, Craig, \& Washington, 2004), age and gender (Craig \& Washington, 2004; Horton-Ikard \& Miller, 2004) of the speaker. Furthermore, the relation between AAVE use and language and literacy skills was more complex than once thought.

Schools, in addition to researchers, have adopted a different theory toward AAVE speakers, and have reexamined their assessment techniques for determining AAVE students who may be at academic risk or who demonstrate needs for additional academic assistance. Rather than assessing how AAVE speakers may differ, however, such programs focus on awareness of differing languages or dialects (Siegel, 2006), and recognize AAVE as an additional language, or a culturally-rich dialect. This awareness allows educators to instead assess proficiency of SAE use as a standalone concept while encouraging the use of the student's primary language. Therefore, rather than assessing language AAVE literacy skill deficits or differences, it is suggested that educators instead focus on assessing SAE literacy skills.

Interventions for general language and literacy impairments of AAVE speakers once included, and may still include, remediation of critical aspects of language development, such as modifying accents and focusing on syntax. Remediation of these critical aspects of AAVE speakers stems from the belief in the deficit theory, in that child AAVE users demonstrate deficient language and other literacy skills. However, considering this not to be the case, remediation of AAVE speaking children is a sensitive subject, given that careful consideration must be taken to understand both the cultural and language development components of AAVE users. Having noted that AAVE use is not related with deficient literacy skills, interventions should not be focused on remediation attempts to erase AAVE dialectical differences (Stockman, 2010). Such interventions devalue the African American culture as a whole, and the family and community of which the students are engaged (LeMoine, 2001). Rather, culturally sensitive interventions must understand that AAVE use connects these speakers with their communities and cultures, and that parsing these ties would be a drastic, and unnecessary measure.

Successful remediation attempts for literacy skills of AAVE speakers, therefore, may lie in the remediation of SAE proficiency. The Academic English Mastery Program (AEMP) within the Los Angeles Unified School District, developed in 1989, is a research-based program that serves all students not proficient in SAE (Beaulieu, 2002; LeMoine, 2001). With particular attention to African American students, concepts the program stresses include teaching the importance of building students' knowledge and understanding of AAVE while remediating SAE skills, approaching SAE instruction as similar to learning a second language, and embodying the experience of learning SAE within the culture and experience of the students (LeMoine, 2001). Similarly, the Dekalb County Schools in Georgia focus on enhancing SAE learning while appreciating AAVE as the home dialect (Beaulieu, 2002). Moreover, they educate the students on communication skills, stressing that the chosen dialect 
is context dependent and encourage dialect switching (Beaulieu, 2002), similar to findings by Connor and Craig (2006).

Additional work suggests that practice transforming written dialect leads to improved SAE writing (Fogel \& Ehri, 2000). Elementary students who were assessed as having AAVE elements in their written work were assigned to one of three research conditions: simple exposure of stories containing SAE elements, exposure to SAE story elements plus explanations for proper SAE use, or exposure to SAE story elements, proper SAE use explanations, and instruction on how to transform AAVE written passages into SAE appropriate passages. Fogel and Ehri demonstrated that children in the third condition, in which all elements were used, were significantly more successful in their SAE writing tasks than either of the other conditions.

Research and programs aimed at assessing and remediating dialectical differences of AAVE speakers have clearly demonstrated that the deficit theory of language and literacy acquisition and performance is obsolete, and are likely based in biased and racist beliefs (LeMoine, 2001). Instead, most current trends examining the assessment and remediation of AAVE speakers recognize a culturally different dialect and language, one that should be embraced and encouraged, while assisting such speakers in the proficiency of both AAVE and SAE education.

\section{Developmental Psychology and African American Vernacular English in the $21^{\text {st }}$ Century}

Developmental psychology's involvement in the research discussed in the previous sections and its contribution to the theoretical debates and discussions on resolutions and legislation and AAVE is virtually non-existent. This seems puzzling given the myriad of theories and methods unique to developmental psychology which could be used to inform research, pedagogy, transition and assessment on AAVE, given the influence of these theories in accounting for typical and atypical social and cognitive outcomes, and given the historical role the discipline has played in contributing to major social policy issues (e.g., Head Start).

The typical theoretical framework guiding research on children who speak AAVE has been grounded in either a comparative difference perspective, or a deficit perspective. As discussed in previous sections of this paper, these perspectives are limiting as they fail to advance or yield knowledge on critical issues germane to the development of language in African American children in general and African American children who speak AAVE in particular. Hence scholars, researchers, and practitioners are unable to address critical developmental questions about the origin, production and maintenance of AAVE and to develop methods that would effectively support these children as they transition from AAVE to SAE. While there are formal (Chomsky, 1965) and functional (Pinker 1984) theories of language development, these theories have been used largely to explain the pattern of language acquisition in SAE speakers. Absent from these approaches is the description of the language development of speakers who vary from SAE and the consideration of the sociocultural influences on the language performance of speakers who vary from SAE.

Developmental theories could fill this knowledge gap in several ways. First, the theories could be instrumental in advancing knowledge about the emergent features of AAVE and providing a framework for determining the "point in time" that children naturally switch between AAVE and SAE. It may be the case that remediation efforts designed to support transitioning could be offered during this "critical period" or "developmental window." Second, the theories could assist in developing a knowledge base, addressing how those features change with time and explore how the features of AAVE change in relation to other cognitive and social capabilities. Third, the theories could provide an answer to a very basic question, "how much intervention is needed before there is consensus that children who speak AAVE are proficient in SAE?"

There are three developmental theoretical perspectives which could serve as useful frameworks to guide future research on AAVE. Each theory described below addresses a specific developmental issue (e.g., origin, production, and maintenance; assessment and transition; socio-emotional issues and AAVE) and posits a distinct set of questions. Furthermore, these theoretical perspectives move beyond viewing the language competence of African American children as a cultural deficit or a cultural difference and acknowledge the independent and collective sociocultural contributions, the learning challenges, and the influence of socioemotional factors of AAVE speaking children.

\subsection{Sociocultural Theory}

The first is perspective is Vygotsky's Sociocultural Theory (Vygotsky, 1978). Central to this theory is the acknowledgement of the vital role that culture plays in defining cognitive competence, shaping the cognitive curricula for children and providing opportunities to develop cognitive skills. This framework is uniquely suited to studying AAVE, given the historical, social and political roots of AAVE, and given the theory's emphasis on 
the sociocultural roots of cognition. That is, children who speak AAVE participate in language activities in their churches (Scott, 2001), homes, families, and neighborhoods, and those language activities are grounded in cultural rituals and traditions maintained by specific cultural socialization practices. By employing this perspective investigators could design research to explore the origin, production and maintenance of AAVE. With the exception of the early work by Ward (1986) and Heath (1989), there is little contemporary information on the origin of AAVE or how it is produced and maintained in speakers' homes or cultural environments. Studies using this framework could explore such questions as to how AAVE is maintained in the home environment, what are the various cultural settings that support AAVE, and at what point in time are children effective in switching back and forth between AAVE and SAE in their home environments? The theory's emphasis on the importance of dyadic learning would permit researchers to examine the role of explicit and implicit parental teaching practices and the development of AAVE.

A core construct of the Vygotskian Theory is the zone of proximal development (ZPD). The ZPD provides an estimation of children's learning potential and provides guidance on the methods and techniques needed to scaffold children's mastery of news skills (Miller, 2010). More recent approaches to the ZPD have specified the role of the teacher and their contribution to the children's ZPD. In contrast to traditional pedagogical perspectives on teacher involvement in learning, the teacher in the ZPD serves as a coach, mentor, and mediator in facilitating children's acquisition of new skills. Because of its use as an assessment tool in education, the ZPD could be used to identify AAVE speaker's initial proficiency in SAE, and to determine the appropriate "dose" of instruction to assist them to transition from AAVE to SAE. The teacher's role is to scaffold the level of instruction and to make adjustments based on students' performance, and mastery of SAE skills.

\subsection{Information Processing Theory}

The second perspective is the Working Memory Perspective as proposed by Baddeley (2000). The model has been used in previous work on typical and atypical language learning and emphasizes the importance of the role of working memory in language and literacy related activities (Baddeley, 2003). The model also situates language as an integral part of the cognitive system in contrast to the formal and functional theories of language learning and in contrast to the traditional information processing model, views cognition as a continuous process, with learners receiving continual feedback about their performance.

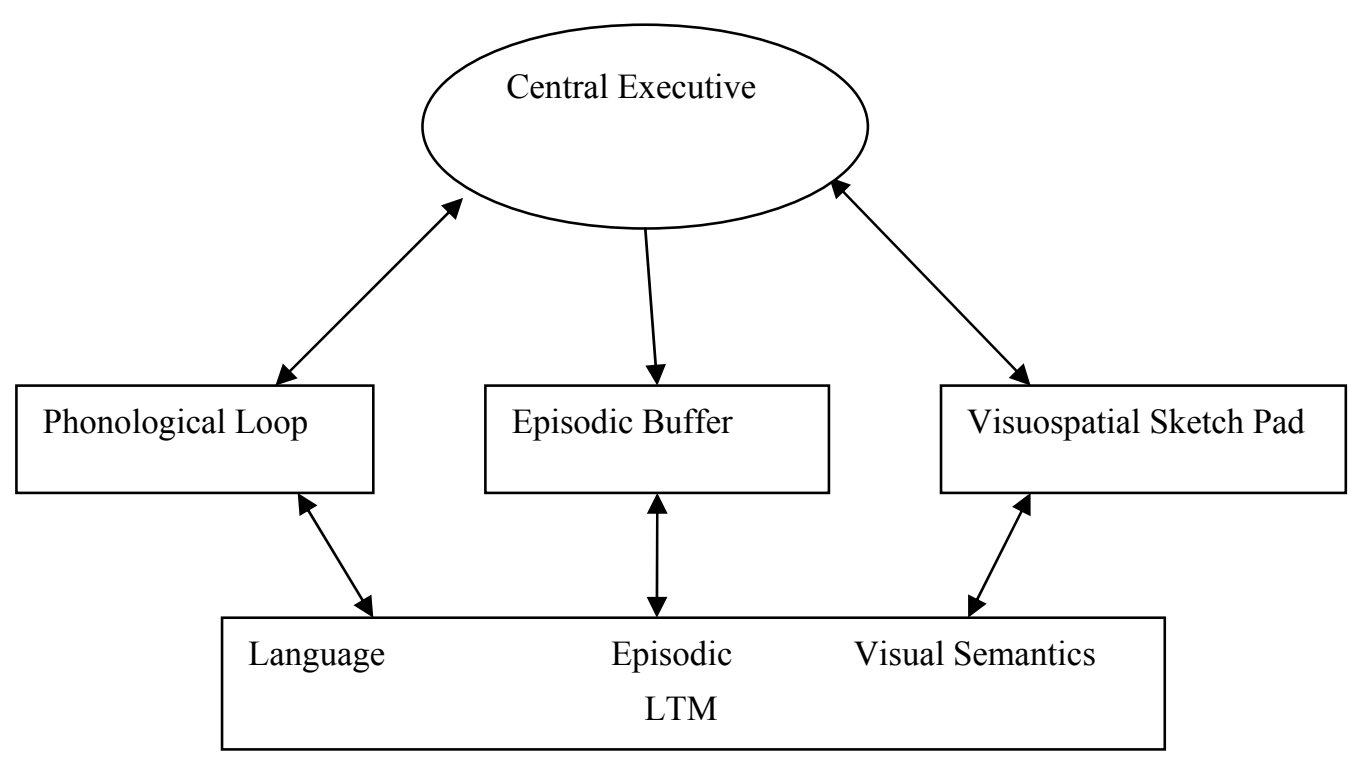

Figure 1. A flow diagram of the memory system (Baddeley, 2000)

The model as briefly illustrated in Figure 1 consists of the central executive system and three limited capacity subsystems. The central executive functions essentially as a "traffic cop." That is, its primary role is to allocate resources to the subsystems, and coordinate the activities of the subsystems and coordinate the communication between the subsystems. The phonological loop is the "auditory" subsystem of the model and is important in the perception of speech sounds and speech production and processes and retains speech sounds for a short duration. 
Adjacent to the phonological loop is the visuospatial sketchpad which processes and retains visual and spatial information for a limited time. Located between the phonological loop and the visuospatial sketchpad is the episodic buffer which stores specific instances of contextual events (i.e. personal events experienced in our lives) and enables learners to connect phonological information with visual information such as the skills needed to sound out words or engage in oral reading activities. Thus the episodic buffer functions to integrate both auditory and visual information. For a full discussion of the model see Baddeley (2000).

How then would this model aid us in understanding the experiences of children who speak AAVE and are transitioning to SAE? Figure 2 presents a modified version of the model that may have applicability for investigating the information processing challenges AAVE speakers' encounter as they are transitioning to SAE. The areas ripe for investigation using this model are those activities that involve remembering the alphabet, phonics, retention of reading material, reading comprehension, spelling, vocabulary and writing. In addition, the model is flexible enough to consider the contribution of age, ses, and familiarity with SAE and can look at such issues cross sectionally, longitudinally or microgenetically.

As shown in Figure 2, the overall structure of the working memory system of children who speak AAVE is similar to that of the working memory system of children who speak SAE. However, it may be the case that the information processing demands may be greater for children who speak AAVE and the central execute may work less efficiently as children are in the initial phases of transitioning from AAVE to SAE. As Figure 2 illustrates, speakers of AAVE have both a primary and secondary phonological loop and visuospatial sketchpad. The primary subsystems are responsible for processing information in AAVE, while the latter for SAE. This is plausible given that there are differences between AAVE and SAE in such phonological features as omission of final consonants, and reduction of final consonant clusters, and because the process of decoding SAE and understanding the meaning of words may initially pose a challenge to AAVE speakers transitioning to SAE. By using this model, researchers could pose a series of questions that identify and diagnosis the auditory problems that AAVE speakers might encounter as they learn the auditory features, grammatical features, and syntax features of SAE, such as what are the challenges inherent in encoding, storing and retrieving speech sounds that are vastly different from one's native sounds? Which SAE sounds are the most problematic for AAVE speakers and which are the least? What are the reading (visual challenges) children have as they decode written information and translate that written information into a meaningful context?

Lastly, the figure also includes the episodic buffer. Given that the episodic buffer allows learners to connect new information to their "real life experiences" it may be qualitatively different for children who speak AAVE. That is, there are certain words in AAVE that do not have a shared meaning with SAE (Charity, Scarborough \& Griffin, 2004). An important question to consider is "what are the information processing challenges AAVE speaker's encounter, while engaging in oral reading activities?"

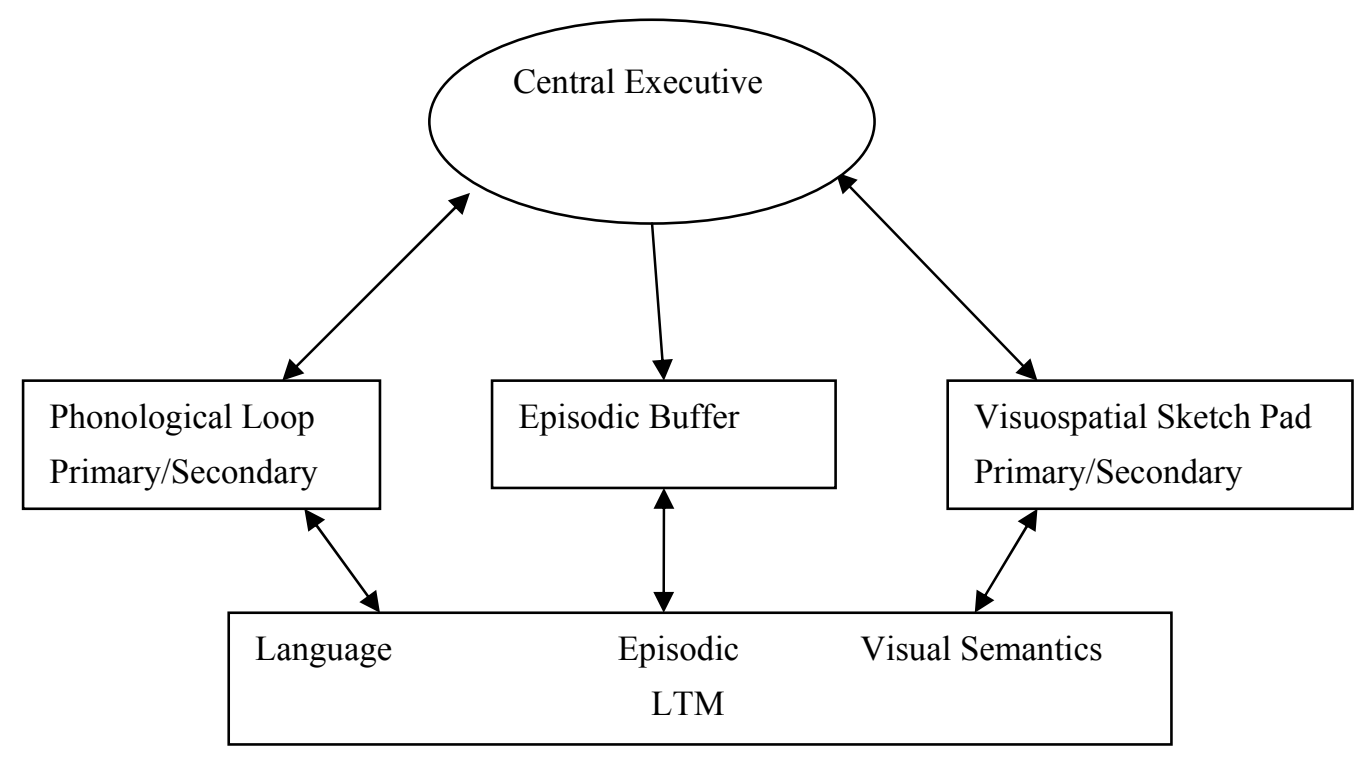

Figure 2. Modified model for speakers of AAVE 
Thus, remediation and instruction designed to aid children who speak AAVE to transition to SAE must be repetitive and planned with the awareness of the "cognitive load" on their existing working memory capacity and based on the previous learning experiences these children have with language in their natural contexts. It may be the case that these children exhibit competence before performance and resource limitations influence their demonstration of proficiency (Adams \& Gathercole, 2000). Furthermore, there may be a great deal of individual variation in the rate at which certain children transition to SAE.

\subsection{Social Cognitive Learning Theory}

There is a wealth of research documenting the influence of socio-emotional factors on learning (Fredericks, Blumenthal \& Paris, 2004). Unfortunately with the exception of the work by Adger and colleagues (1999), little attention has been given to the relationship between socioemotional factors and AAVE. For many children who speak AAVE, their language is a core part of their identity, and serves as an anchor connecting them to their cultural heritage. Speaking a language different from SAE brings with it a psychosocial dimension that can significantly affect children's sense of self worth, self efficacy and identify and ultimately undermine their mastery of material (Bialystok, 2001). Consequently because of the stigma associated with speaking AAVE and teacher feedback, some "disidentify" with the academic process, and exhibit a low effort syndrome (Strambler \& Weinstein, 2010). This is manifested in their devaluing of academic success (I don't care if I don't do well at reading), and their discounting of feedback about their performance (i.e. the teacher gave me a bad grade because $\mathrm{s} /$ he does not like me).

Two concepts from Bandura's Social Cognitive Learning Theory (1997), self efficacy and agency, are particularly suited to exploring how socioemotional factors influence children's transition from AAVE to SAE. Bandura (1997) defines self efficacy as "belief $s$ in one's capabilities to organize and execute a course of action required to produce given attainments." Agency is closely related to self efficacy and involves one's motivation to achieve goals. The theory asserts that children with a high sense of self efficacy are agentic and able to master very difficult and challenging tasks. Children develop their sense of self efficacy from a variety of sources. Those sources include feedback from teachers, and parents about their performance, and their previous performance. This perspective could be used in conjunction with the two other perspectives discussed (i.e., Vygotsky and IPS) and could at minimal investigate such questions as what specific teacher methods used in the children's ZPD enhance their self efficacy and promote their transition to SAE, and what is the relationship between self efficacy, agency and mastery of activities that involves learning and remembering SAE phonological features?

\section{Litigation, Resolutions and African American Vernacular English (AAVE)}

\subsection{The Ann Arbor Black English Case}

The Ann Arbor case was the first major case to address the influence of AAVE on academic achievement (Yelin, 1980). Prior to that time the seminal cases which served to reform educational policy and practice were Brown vs. The Board of Education (1954), the Lau vs. Nicholas case (1974), and Larry P Riles vs. the BOE, and the EEOC case of 1974.

The Ann Arbor case also known as the Martin Luther King Junior Elementary School children et al., vs. the Ann Arbor School District was filed on behalf of parents whose children spoke AAVE, which parents and scholars contended was a distinct language with its own rules for pronunciation, grammar, and syntax. The parents were concerned with the procedures employed by the school district to assess their children, and the criteria used to place their children in special education, and in remedial education classes. The plaintiffs argued that the procedures were inherently flawed and unfairly penalized their children because they failed to take into account the language and cultural background of these children (Labov, 1982).

The defendants on the other hand countered and declared that the children spoke a dialect rather than a separate and distinct language, and "the schools were not legally responsible for the alleged detrimental effects upon the children's failure to learn to read and write" (Yelin, pg 151). The court decided in favor of the plaintiffs and ruled that the Ann Arbor School Board was in violation of Title 20 of the U.S. Code Section 1703 (f): or the language barrier clause of the 1974 Equal Education Opportunity Act. This clause read "No state shall deny equal educational opportunity to an individual on account of his or her race, color, sex, or national origin by: (f) the failure by an educational agency to take appropriate to overcome linguistic barriers that impede equal participation by its students in its instructional programs." The court acknowledged the plausible link between the children's literacy and reading performance and the school districts failure to consider the linguistic and cultural background of these children. 
Two mandates were issued by the court to the Ann Arbor School District. One, develop procedures and protocols to identify those children who spoke AAVE; and two, provide in-service training to teachers to increase their knowledge of the features of AAVE, to introduce them to methods to assess and to identify AAVE and to develop strategies to assist the children in transitioning AAVE to SAE (Labov, 1982).

Scholars drew four general conclusions from the Ann Arbor case. First, the case re-opened the controversial theoretical debate of the deficit vs. difference theory of language which had dominated theory, research and policy for more than two decades. The deficit theory has historically explored social class and racial differences in language performance and identified a host of negative environmental and parenting practices promoting deficit pathways to language competence and development. In contrast, the difference theory affirms that variation exists in the parenting, learning and language environments of low income children and some black children; however that variation does not imply or produce deficient cognitive skills. The second centered on teacher perception of AAVE and student performance. With the advent of desegregation, many Caucasian teachers encountered African American students in their classrooms who spoke a language that they were unfamiliar with (Harris \& Graham, 2007). Consequently, they frequently rated their language patterns as inferior to SAE and assumed that the speech pattern was indicative of intellectual deficiencies. In terms of actual behavior, observers noted that teachers provided less direct instruction to speakers of AAVE either over corrected or under corrected all errors which deviated from SAE and expressed lower expectations for African American student's achievement (Blake \& Cutler, 2003). The third conclusion underscored the need for continued research exploring the relationship between AAVE, language proficiency and literacy skills. Lastly, critics concluded that although the case was one of the first to address barriers faced by students who speak AAVE, the court was reticent in providing a strong endorsement of AAVE as a legitimate language (Baugh, 1995).

Nevertheless, as a result of the court's decision, conferences, and roundtables were convened to discuss the language and literacy performance of African American children. Advocacy groups were assembled to lobby for legislation pursuant to adopting AAVE as a second language; and a rich body of scholarship emerged exploring a myriad of environmental and social influences on AAVE. In addition, programs were implemented in several school districts in Ann Arbor to address the dialect concerns and transitioning dialect speakers to SAE.

\subsection{The Ebonics Resolution}

The Ebonics Resolution issued by the Oakland School Board in 1996, was a directive to the superintendent of schools to "implement a program for imparting instruction to African American students in their primary language for the combined purposes of maintaining the legitimacy and richness of such language....and to facilitate their acquisition and mastery of English language skills" and to make efforts to pursue and secure federal funding to support Ebonics programs (Baron, 2002). The resolution was an effort to address the overall dismal academic performance of African American children on in class literacy measures and on standardized reading assessments. African American children comprised 53 percent of the students in the school district but were overrepresented in special education classes, underrepresented in gifted and talented classes, more likely to be truant, suspended or retained or repeat a grade, and had the lowest grade point average in comparison to other racial and ethnic groups in the district.

The resolution sparked considerable debate among scholars, educators, and politicians, and reignited the deficit versus difference debate about language competence and African American children (Harris \& Graham, 2007). As a result of the controversy, the school board amended the resolution in 1997, deemphasizing AAVE as a separate and distinct language, and changed the primary focus of the resolution to focus on educating teachers about AAVE and equipping them with methods to assist children to transition from AAVE to Standard American English.

In response to the continued need to address the academic performance of African American students in the Oakland School District, in 2006 the California Curriculum Committee encouraged schools to provide "additional support for students who use AAVE who may have difficulty with phonological awareness and standard academic English structures of oral and written language, including spelling and grammar" (Labov \& Hudley, 2008).

What can we conclude about the contribution of the legislation and the resolution to our understanding of AAVE and African American children? Both the Ann Arbor case and the Ebonics resolution, reignited the language deficit versus difference debate, provoked an explosion in books (Whiteman, 1980; Smitherman, 1981; Perry \& Delpit, 1997), research (see Rickford, Sweetland, \& Rickford 2004, for a review) and discourse, and resulted in thoughtful critiques and reviews about language learning, teacher influence and pedagogy (Blake \& Cutler, 2003). There was also a renewed interest in considering the numerous proximal and distal influences (i.e. home 
and neighborhood environments, teacher beliefs, quality of the schools attended by children who speak AAVE attend) on their language performance and overall academic achievement. Thus the legislation and the resolution forced researchers, educators, speech pathologists to revisit theoretical debates and questions about African American children, the achievement gap, and AAVE

\section{Conclusion}

In conclusion, the language and academic life of African American children who speak AAVE has been the topic of considerably controversy for more than four decades. The focus of this paper was to discuss the legislation and resolutions that dominated much of the discourse on African American children and language learning, and ultimately served to determine many of the developmental outcomes and pathways for African American children. Another focus was to describe the developmental trends in language learning, and efforts used to remediate and transition these children to SAE; and to discuss the potential role of developmental psychology in filling a much needed gap in theory and research on children who speak AAVE and move the discussion beyond a deficit or comparative difference framework.

For the $21^{\text {st }}$ century any discussion and resulting research on children who speak AAVE, must take into account the sociocultural and historical factors that shape their language use, the information processing challenges they may experience as they transition from AAVE to SAE, and the role that their self efficacy and sense of agency play in influencing their mastery of new language skills. Furthermore it is important that these results be used to contribute to a new social policy agenda that emphasizes the development and implementation of inclusive, comprehensive reform in language education policy, critical language pedagogy, and teacher preparation programs in language and literacy education (Ball \& Akim, 2005).

\section{References}

Adams, A., \& Gathercole, S. E. (2000). Limitations in working memory: Implications for language development. $\begin{array}{lllll}\text { International Journal of Communication } & \text { Disorders, } & 35, & 95-116 .\end{array}$ http://dx.doi.org/10.1080/136828200247278

Baddeley A. (2000). The episodic buffer: A new component of working memory? Trends in Cognitive Science, 11, 417-423. http://dx.doi.org/10.1016/S1364-6613(00)01538-2

Baddeley, A. (2003). Working memory and language: an overview. Journal of Communication Disorders, 36, 189-208. http://dx.doi.org/10.1016/S0021-9924(03)00019-4

Ball, A. F., \& Alim, H. S. (2006). Chapter 6 preparation, pedagogy, policy, and power: Brown, the King Case, and the Struggle for Equal Language Rights. Yearbook of the National Society for the Study of Education, 105, 104-124. http://dx.doi.org/ 10.1111/j.1744-7984.2006.00078.x

Bandura, A. (1997). Self efficacy: The exercise of control. New York: W. H. Freeman.

Baron, D. (2000). Ebonics and the politics of English. World Englishes, 19, 5-19. http://dx.doi.org/10.1111/1467-971X.00152

Baugh, J. (1995). The law linguistics, and education, Educational reform for African language minority students. Linguistics and Education, 7, 87-106. http://dx.doi.org/10.1016/0898-5898(95)90002-0

Beaulieu, L. M. (2002). African American children and literacy: Moving past the Ebonics debate to a common understanding. In S. J. Denbo, \& L. M. Beaulieu (Eds.), Improving schools for African American students: A reader for educational leaders. Springfield, IL: Charles C. Thomas Publisher, LTD.

Bialystok, E. (2001). Bilingualism in development. Language, literacy, and cognition. New York: Cambridge University Press.

Blake, R., \& Cutler, C. (2003). AAE and variation in teachers' attitudes: A question of the school philosophy? Linguistics and Education, 14, 163-194. http://dx.doi.org/10.1016/S0898-5898(03)00034-2

Brice-Heath, S. (1988). Language socialization. New Directions for Child Development, 42, $29-41$.

Campbell, T., Dollaghan, C., Needleman, H., \& Janosky, J. (1997). Reducing bias in language assessment: Processing-dependent measures. Journal of Speech \& Hearing Research, 40, 519-525.

Charity, A. H., Scarborough, H. S., \& Griffin, D. M. (2004). Familiarity with school English in African American children and its relation to early reading achievement. Child Development, 78, 1340-1356. http://dx.doi.org/10.1111/j.1467-8624.2004.00744.x

Chomsky, N. (1965). Aspects of the theory of syntax. MA: MIT Press. 
Connor, C. M., \& Craig, H. K. (2006). Africa American preschoolers' language, emergent literacy skills, and use of African American English: A complex relation. Journal of Speech, Language, and Hearing Research, 49, 771-792. http://dx.doi.org/10.1044/1092-4388(2006/055)

Federal Interagency Forum on Child and Family Statistics. (2008). American's children: Key national indicators of well-being. Washington, DC: U.S. Government Printing Office.

Fredericks, J. A., Blumenfield, P. C., \& Paris, A. H. (2004). Social engagement: Potential of the concept, state of the evidence. Review of Educational Research, 74, 59-209. http://dx.doi.org/10.3102/00346543074001059

Graham, S. (1992). "Most of the participants were White and middle class": Trends in published research on African American in selected APA journals, 1970-1989. American Psychologist, 47, 629-639.

Gravois, T. A., \& Rosenfield, S. A. (2006). Impact of instructional consultation teams on the disproportionate referral and placement of minority students in special education. Remedial and Special Education, 27, $42-52$.

Harris, Y. R., \& Graham, J. A. (2007). The African American Child. New York: Springer Publishing Company.

Horton-Ikard, R., \& Miller, J. F. (2004). It is not just the poor kids: The use of AAE forms by African-American school-aged children from middle SES communities. Journal of Communication Disorders, 37, 467-487. http://dx.doi.org/10.1016/j.jcomdis.2004.02.001

Labov, W. (1982). Objectivity and commitment in linguistic science: The case of the Black English trial in Ann Arbor. Language in Society, 11, 165-201. http://dx.doi.org/10.1017/S0047404500009192

Labov, W., \& Hudley, A. C. (2009). Symbolic and Structural Effects of Dialects and Immigrant Minority Languages in Explaining Achievement Gaps. Paper prepared for the Workshop on the Role of Language in School Learning: Implications for Closing the Achievement Gap, October 15-16, Hewlett Foundation, Menlo Park, CA.

LeMoine, N. R. (2001). Language variation and literacy acquisition in African American students. In J. L. Harris, A. G. Kamhi, \& K. E. Pollock (Eds.), Literacy in African American communities. Mahwah, NJ: Lawrence Erlbaum Associates, Publishers.

McLoyd, V. C. (1990). The impact of economic hardship on Black families and children: Psychological distress, parenting, and socioemotional development. Child Development, 61, 311-346. http://dx.doi.org/ 10.1111/j.1467-8624.1990.tb02781.x

Miller, P. H. (2011). Theories of developmental psychology (5th ed.).NY: Worth Publishers.

Perry, T., \& Delpit, L. (1997). The real ebonics debate: Power, language and the education of African American children. Boston: Beacon Press.

Pinker, S. (1984). Language learnability, and language development. Cambridge MA: Harvard University Press.

Rickford, J. R., Sweetland, J., \& Rickford, A. E. (2004). African American English and other vernaculars in education. Journal of English Linguistics, 32, 230-320. http://dx.doi.org/ 10.1177/0075424204268226

Scott, G., \& Marcus, C. (2001) Emergent literacy: Home School connections. In J. Harris, A. Kamhi, \& K. Pollock (Eds.), Literacy in African American Communities (pp. 77-97). Mahwah, NJ: LEA.

Siegel, J. (2006). Language ideologies and the education of speakers of marginalized language varieties: Adopting a critical awareness approach. Linguistics and Education, 17, 157-174. http://dx.doi.org/ 10.1016/j.linged.2006.08.002

Smitherman, G. (1981). Black English and the education of black children and youth. Proceedings of the National Symposium on the King Decision. Detroit, MI: Center for Black Studies, Wayne State University.

Stockman, I. J. (2010). A review of the developmental and applied language research on African American children: From a deficit to a difference perspective on dialect differences. Language, Speech, and Hearing Services in Schools, 41, 23-38. http://dx.doi.org/ 0.1044/0161-1461(2009/08-0086)

Strambler, M. J., \& Weinstien, R. S. (2010). Psychological disengagement in elementary school among ethnic minority students. Journal of Applied Developmental Psychology, 31, 155-165. http://dx.doi.org/10.1016/j.appdev.2009.11.006

Terry, N. P., Connor, C. M., Thomas-Tate, S., \& Love, M. (2010). Examining relationships among dialect variation, literacy skills, and school context in first grade. Journal of Speech, Language, and Hearing Research, 53, 126-145. http://dx.doi.org/10.1044/1092-4388(2009/08-0058) 
U.S. Department of Education. (2010). Actual and projected numbers for enrollment in public elementary and secondary schools, by race/ethnicity: Fall 1994 through fall 2019. Retrieved March 8, 2011, from http://nces.ed.gov/programs/projections/projections2019/tables/table_03.asp?referrer=list

Vygotsky, L. S. (1978). Mind in Society. The development of higher psychological processes. Cambridge MA: Harvard University Press.

Ward, M. (1986). Them children: A study in language learning. Prospect Heights, IL: Waveland Press.

Whiteman, M. (1980). Reactions to Ann Arbor: Vernacular black english and education. Arlington, VA: Center for Applied Linguistics.

Yelin, D. (1980). The Black English Controversy: Implications form the Ann Arbor Case. Journal of Reading, 2, $150-154$. 